\title{
GAME TEAM CREATION AS A MOTIVATING ACTIVITY IN A DISCIPLINE OF PROBABILITY AND STATISTICS FOR ENGINEERING
}

\author{
Ana Paula Silva Figueiredo, Rennan Muniz Pereira \\ Universidade Federal de Itajubá, Brasil \\ anapaula@unifei.edu.br
}

\section{INTRODUCTION}

This paper presents the development of a team game activity for the course of Probability and Statistics that was held in the first day of class of an Engineering program to motivate students. This course is sometimes described as dense and considerably difficult, so students may be somewhat apprehensive. Thus, this activity aimed to break with such predisposition.

THE GAME

The students were divided in teams of 6 , and each member played a role (player, coach, strategist, reporter, trainer and leader). The students were supposed to develop a game with either coins or dice. The team would have to describe the rules and calculate the expected value of the game. All the members should work on the development of their team's game, but each of them had a role: the strategist should simulate the game and analyze it; the reporter would describe the rules and the calculated expected value. The trainer had to describe their game to the class, giving enthusiastic clues about it. Each team formed two sub-groups, those who played and those who were on the betting table. The player and his/her coach would play the other games in class. The leader should conduct all the teamwork.

The trainer of each team had time to explain the game to the class. His/her intention would be to motivate the other players to come to their table and play the game on his/her team. Each team created its own betting table, not exactly like in a casino, but a fake one, as seen in figure 1.

Each team had 15 credits, which were divided between the player and the betting table. The player and the coach of each team played the games of the other teams. The winner was the team that won more credits. On figures $1 \mathrm{a}$ and $1 \mathrm{~b}$, it is possible to see the students playing the game.

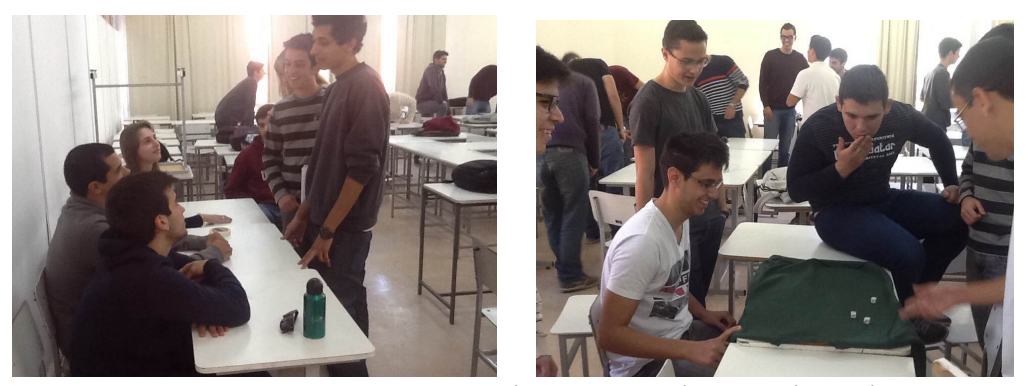

Figure 1 - The gaming class.

\section{THE TEAM AND STATISTICS COMPETENCIES LEARNED}

During this activity, the students developed the competence to work in teams, which is desired for students and future engineers. On teamwork, each member is assigned explicit tasks that should be done in order to achieve the goal. On this activity, the students had the opportunity to discuss their results concerning to the game and they could identify which role was better played, in special regarding the player, the coach and the strategist. However, they did not leave critics aside on the leader of the team where he/she did not conduct the job with effort. The other role, which had critics, was the trainer about whom the team said he/she had not given a very good explanation of their game and did not attract much players, so their betting table was somewhat empty. They explained also the strategies (and the lack) who made a team win (or fail). On Statistics competencies perspectives they showed an intuition on expected value meaning, a concept that was developed along the course. One of the students reported, "The experience of holding a game involving statistical concepts was a great way to introduce the course and the integration of students who did not know themselves, and sparked interest in the discipline. This kind of activity should be expanded to other courses on the university". 